\title{
Design and Implementation for optical fiber communication system using frequency shift coding
}

\author{
Samar Y.Al-Dabagh* \\ Hani J.Kbashi**
}

Received 16, December, 2008

Accepted 23, June, 2009

\begin{abstract}
:
In this research, optical communication coding systems are designed and constructed by utilizing Frequency Shift Code (FSC) technique. Calculations of the system quality represented by signal to noise ratio $(\mathrm{S} / \mathrm{N})$, Bit Error Rate (BER), and Power budget are done.

In FSC system, the data of Nonreturn- to-zero (NRZ) with bit rate at 190 $\mathrm{kb} / \mathrm{s}$ was entered into FSC encoder circuit in transmitter unit. This data modulates the laser source HFCT-5205 with wavelength at $1310 \mathrm{~nm}$ by Intensity Modulation (IM) method, then this data is transferred through Single Mode (SM) optical fiber. The recovery of the NRZ is achieved using decoder circuit in receiver unit.

The calculations of BER and S/N for FSC system at maximum fiber length at 61.2 $\mathrm{km}$ equal to $2.30551 \times 10^{-12}, 47.88526 \mathrm{~dB}$ respectively. The power budget for FSC system was calculated to be $29 \mathrm{~dB}$.

Results show that the BER increases when the received optical power decreases the due to increase of the optical fiber length61.2 km. while $\mathrm{S} / \mathrm{N}$ decreases. The optical power budget increases as the transmitted optical power increases.
\end{abstract}

Key words: optical fiber, coding, frequency shift, digital communication

\section{Introduction:}

Diverse communication and signal processing technologies utilize specially coded signal formats in order to achieve desirable capabilities such as error correction, interference rejection, and secrecy. In 1963, in an effort to standardize data communication codes, the United States adopted the bell system model 33 teletype code as the United States of America Standard Code for Information Interchange (USASII), better known simply as ASCII-63. ASCII is a 7-bit character set which has 128 combinations that means 7 bits in every block [1]

Since conventional NRZ code can prove unsuitable, especially for high data rate, for transmitting data in optical fiber, the best pattern for high

* College of Science for Women, Phys. Dept. Baghdad Un.

**College of Science, Phys. Dept., Baghdad Un. speed transmission is Manchester coding or frequency shift coding . Manchester transmission is alternate $1 \mathrm{~S}$ and $\mathrm{OS}$ while the best pattern for high speed frequency shift transmission is all Zeros, as shown in figure 1. FSC waveform shows that the levels change at the leading edge of each bit regardless of the bit value. For ones, encoder give an additional change at each bits center ,zero have no second level change per bit[2] .

The main purpose of Frequency Shift encoder is to convert the NRZ data waveform into FSC data waveform with the transition at center bit for each logic 1 bits from NRZ data, and in addition to transition at leading edge, for each 0 from NRZ data . 
There are three major multiple access approaches .Each user is allocated a specific frequency (wavelength)solt in Wavelength-Division Multiplexing (WDM).Both techniques have been extensively explode either using Wavelength-Division Multiplexing (WDM) or Time Division Multiplexing(TDM). Alternatively Optical Code Division Multiplexing (OCDM)is an alternative technique that take the advantage of the enormous bandwidth in single mode fiber to achieve random asynchronous communication access among many user, free of net work control [3]. Meagher B.al. design and demonstrated ultra low optical switching for WDM network[4]. Every user is assigned a specific code sequence. Through a proper choice of the OCDM codes, the signals from all network nodes can be made mutually noninterferining the incoherent OCDM. In encoder map each bit "1" of source information into a high bit rate optical sequence of ultra short light pulses, while the bit" 0 " is not encoded . D.E Leaird et al. have demonstrated spectrally phase coded OCDM with a modulation format based on switching between two codes[5].A code switching security provide enhanced in OCDM and this technology could be utilize for a high capacity. Z.Jiang etal have demonstrated a $2.5 \mathrm{~Gb} / \mathrm{s}$ four user, OCDMA system be rate at bit rate $<10^{-}$ ${ }^{11}$ [6] and a wide band Frequency shift keying(FSK)have been demonstrated by Main and chun z in2006 [7]

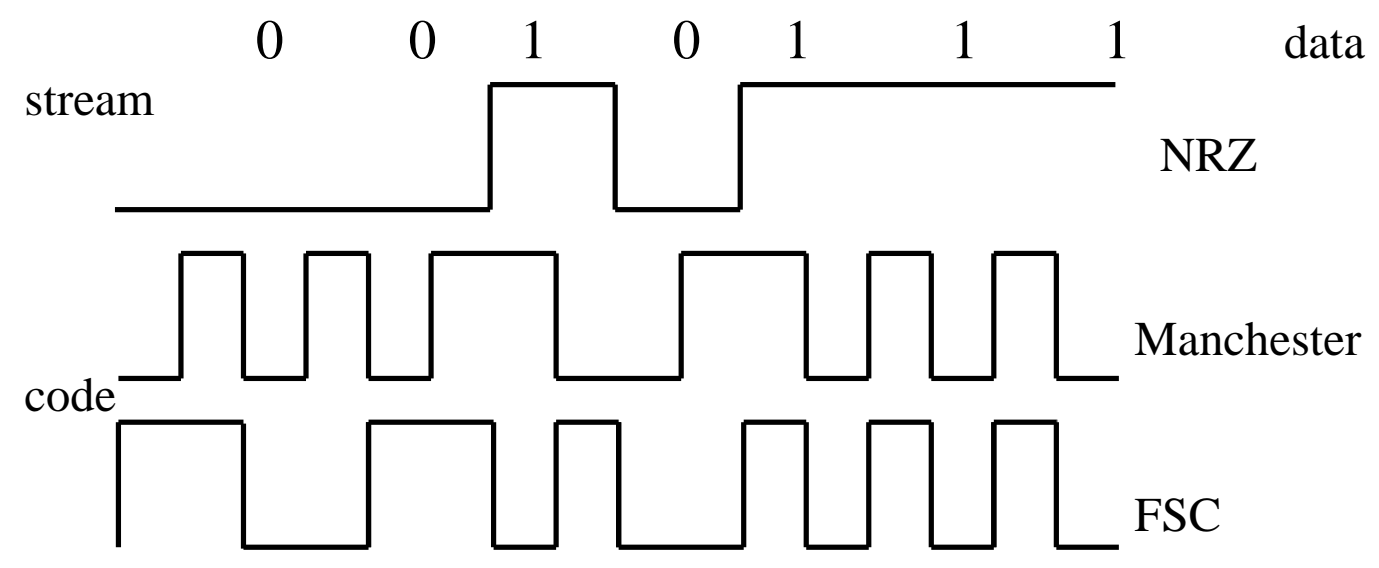

Fig.(1)Some methods of coding binary data

\section{Materials and Methods:}

Shift code system is shown in figure 2 .This figure shows the principle components of the link which contains the transmitter(encoder and modulator), the receiver( demodulator and decoder), and the optical fiber as transmission channel for the link. A NRZ data rates at $190 \mathrm{kbits} / \mathrm{s}$ was entered into FSC encoder. This NRZ data that generated by voice communication represented by time division multiplexing system (TDM). The optical source which provide the electrical-optical conversion is a semiconductor laser diode(LD), The package of this laser is designed to allow repeatable coupling into single mode optical fiber. Frequency shift code signal is used to drive an optical source $(1310 \mathrm{~nm})$ using Intensity Modulation (IM). This laser spectral width is $1 \mathrm{~nm}$, optical rise time is 2 nsec, and the average optical output power is $-10 \mathrm{dBm}$ that was measured by using optical power meter OPM4. 


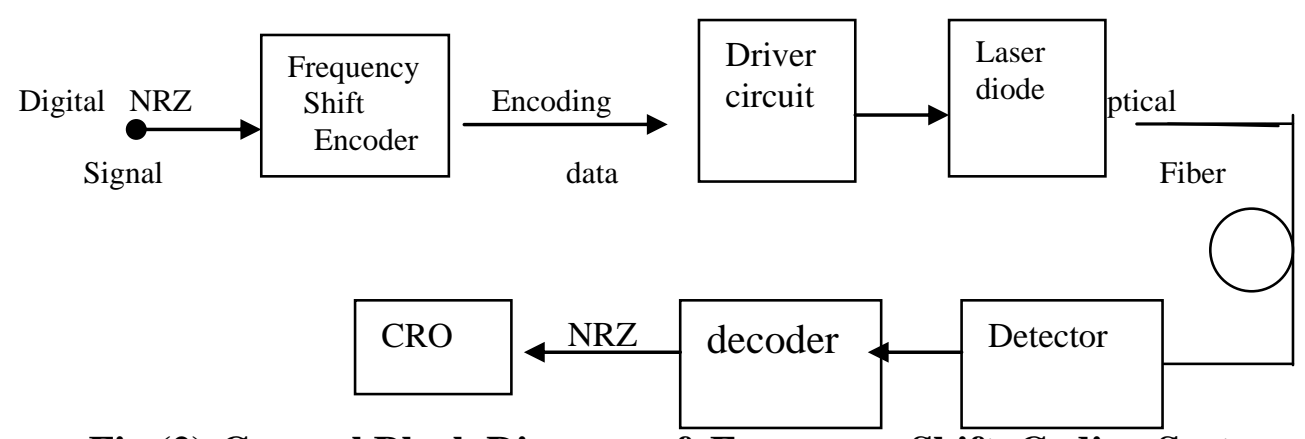

Fig.(2):General Block Diagram of Frequency Shift Coding System

The specification of the fiber that used in this system are core to cladding diameter equal to $10 / 100$ micrometer, the whole all diameter is $3.2 \mathrm{~nm}$, the attenuation is $0.2 \mathrm{~dB}$ for wavelength at $1310 \mathrm{~nm}$, the numerical aperture is 0.14 and the acceptance angle is $8.05^{\circ}$.
The receiver consists of an optical detector which drives a future electrical stage and hence provides demodulation of the optical carrier. PIN photodetector was used in the receiver unit. Figure 3 shows the block diagram of the Frequency Shift decoder

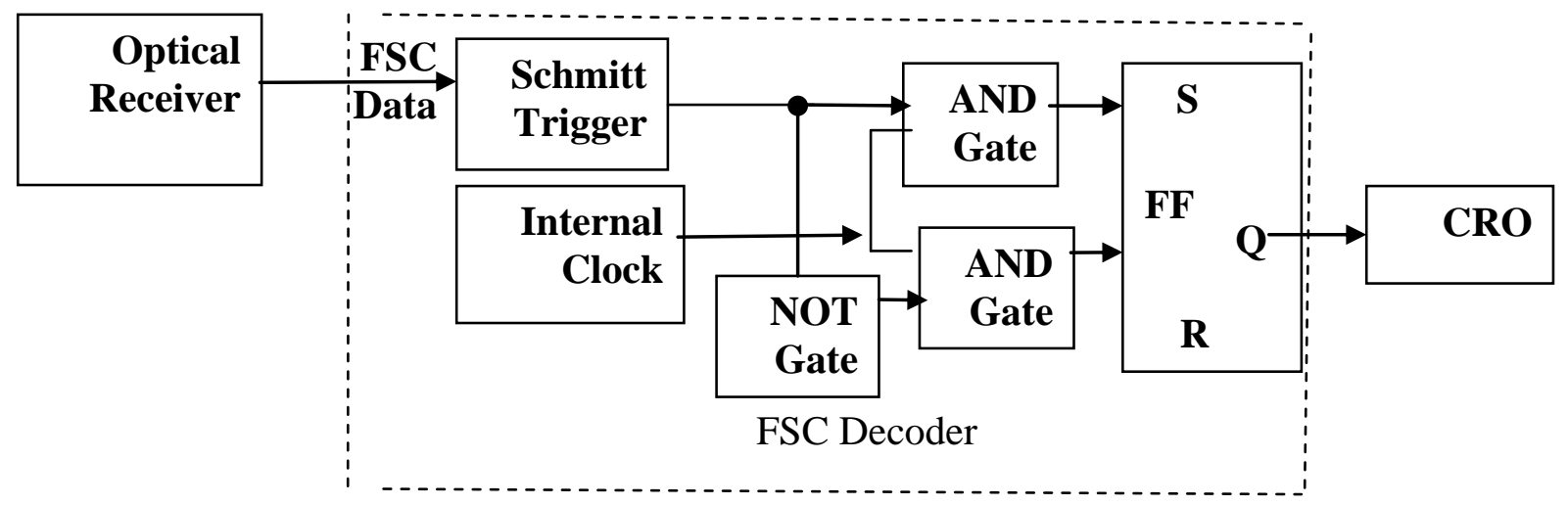

Fig.(3):Block diagram of the receiver unit of FSC .

\section{Calculation and Results:}

The waveforms from the Cathode Ray Oscillscope (CRO) of the input NRZ data and the output data FSC of the transnitter unit are shown in figure 4.

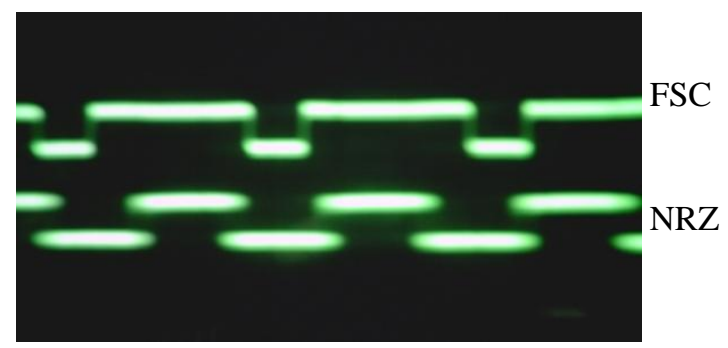

Fig.(4):the waveforms of NRZ and FSC signal with scale time set to 0.5 $\mu \mathrm{s} / \mathrm{div}$.
The received pulses (FSC data) and the decoded NRZ signal waveforms are illustrated in figure5

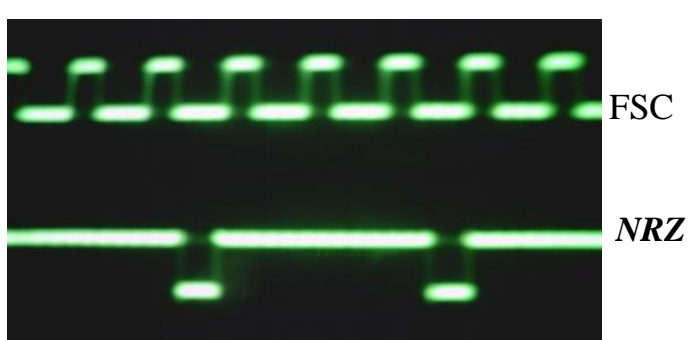

Fig. (5):The waveforms of FSC and NRZ signals of FSC decoder with scale time set to $0.5 \mu \mathrm{s} / \mathrm{div}$. 


\section{A-Computing of BER of FSC Receiver:}

In order to determine the system quality, we calculate for the BER of the system in digital transmission. Is done. Performance is based on $\mathrm{BER}$, which is the percentage of error bits received. BER as function of $\mathrm{S} / \mathrm{N}$ of digital signal is given by[8]

$\mathrm{BER}=1 /(6.28 \mathrm{~S} / \mathrm{N})^{1 / 2} \times \operatorname{EXP}(-\mathrm{S} / \mathrm{N} / 2)$ ...(1)

where $\mathrm{S} / \mathrm{N}$ is defined as

$\mathrm{S} / \mathrm{N}(\mathrm{dB})=20 \log (\mathrm{Is} / \mathrm{In}) \quad \ldots(2)$

The signal current generated in the detector is Is and is written as

Is $=\operatorname{Prec} \times \mathrm{R}_{\lambda}$
Where $p_{\text {rec }}$ is the incident optical power .For HFCT - 5205 transceiver PIN photodiode ,the responsivity $R_{\lambda}$ is equal to $0.36 \mathrm{~A} / \mathrm{W}$

and the total noise current In is written as

$\mathrm{In}=\mathrm{Ith}+$ Ishot $+\mathrm{Id}$

The noise originating in the detector are thermal noise current (Ith), shot noise current (Ishot) and dark current(Id) equal to $4 \mathrm{nA}$. The photodiode load resistor(RL) $20 \mathrm{k} \Omega$.

Calculations of BER based on a practical measurements of the received optical power at different values of the single mode optical fiber length of frequency shift code signal waveform are shown in table (1)

Table(1):The BER values as a function of fiber length, $\mathrm{S} / \mathrm{N}$, ith ,I shot and prec for SM optical fiber channel with FSC system

\begin{tabular}{|c|c|c|c|c|c|c|c|}
\hline$=(\mathrm{km})$ & prec (mw) & $S(N A)$ & $\operatorname{sth}(N A)$ & tshot $(N A)$ & $\ln (N A)$ & $S / N(d B)$ & $B E R$ \\
\hline 1 & 0.1 & 36000 & 0.396636 & 1.47946 & 5.8761 & 75.74427 & 1.63563E- 18 \\
\hline 5.1 & 0.0733 & 26400 & 0.396636 & 1.26665 & 5.66328 & 73.36677 & $5.45606 \mathrm{E}-18$ \\
\hline 10.2 & 0.05978 & 21500 & 0.396636 & $1.1438: 8$ & 5.54052 & 71.78616 & $1.21572 \mathrm{E}-17$ \\
\hline 15.3 & 0.0348 & 12500 & 0.396636 & 0.872756 & 5.26939 & 67.52243 & $1.05679 E-16$ \\
\hline 20.4 & 0.03195 & 11500 & 0.396636 & 0.836255 & 5.23289 & 66.84063 & $1.49362 \mathrm{E}-16$ \\
\hline 25.5 & 0.0223 & 8030 & 0.396636 & 0.698643 & 5.09528 & 63.94879 & $6.48338 \mathrm{E}-16$ \\
\hline 30.6 & 0.01989 & 7160 & 0.396636 & 0.659812 & 5.05645 & 63.02183 & $1.03814 \mathrm{E}-15$ \\
\hline 35.7 & 0.01592 & 5730 & 0.396636 & 0.590302 & 4.98694 & 61.20823 & 2.60866 E-15 \\
\hline 40.8 & 0.01216 & 4380 & 0.396636 & 0.515905 & 4.91254 & 58.9986 & $8.02078 E-15$ \\
\hline 45.9 & 0.00837 & 3010 & 0.396636 & 0.428022 & 4.82466 & 55.91123 & $3.85746 \mathrm{E}-14$ \\
\hline 51 & 0.00706 & 2540 & 0.396636 & 0.393102 & 4.78974 & 54.49591 & $7.9287 E-14$ \\
\hline 56.1 & 0.00409 & 1470 & 0.396636 & 0.299202 & 4.69584 & 49.926 .25 & $8.13781 \mathrm{E}-13$ \\
\hline 61.2 & 0.00321 & 1160 & 0.396636 & 0.265067 & 4.6617 & 47.88526 & 2.30551E-12 \\
\hline
\end{tabular}

Table 1 shows the calculated results of the single mode optical fiber channel, which clarify noise current and data BER. The BER is increasing as the fiber length increasing. The acceptable order value of the BER in optical digital transmission is $10^{-} 9$.It is clear that the value of the BER of FSC system is equal to $2.355 \times 10^{-12}$ at optical fiber length of $61.2 \mathrm{~km}$ is acceptable, then the received optical power at this length doesn't need any amplifying by optical amplifier while $\mathrm{S} / \mathrm{N}$ for FSC system at $61.2 \mathrm{~km}$ equal to $47.88526 \mathrm{~dB}$.

From this table results, may conclude that the $\mathrm{S} / \mathrm{N}$ is decreasing by increasing the fiber length as shown in figure 6. Although the $\mathrm{S} / \mathrm{N}$ is decreasing, the value of the $\mathrm{S} / \mathrm{N}$ is acceptable for fiber length longer than $61.2 \mathrm{~km}$. 


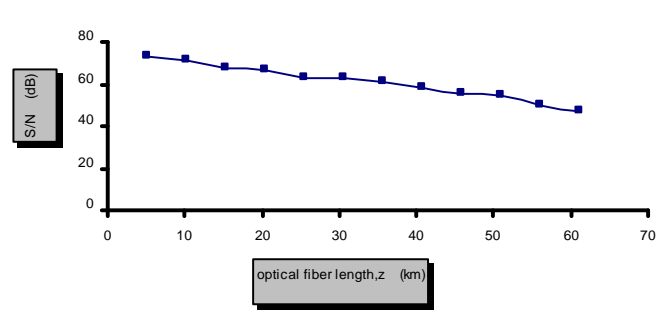

Fig.(6) :The relation ship between the Signal to Noise Ratio(S/N) with the optical fiber length,$Z$ in single mode optical fiber channel of Frequency shift code system.

The relationship between the BER with the received optical power as a function of fiber length of the SM optical fiber in FSC system is shown in figure 7

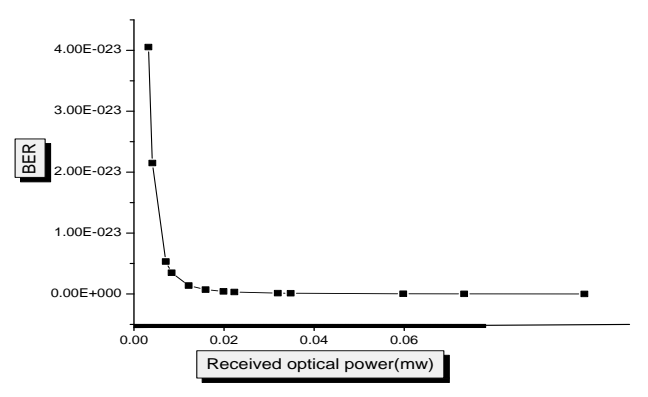

Fig. (7) :The relation ship between the logarithm of BER with the received optical power in single mode optical fiber channel of Frequency shift code system.

\section{B-Optical Power Budget}

To ensure that the optical fiber system has sufficient power for correct operation, the power budget must be calculated, the power budget is given by[9]

Power budget $(d B)=10 \log \frac{P t x}{P \min }$

Or Powerbudget $(d B)=p t x(d B)-p \min (d B)$

... (5)

Powerbudget $(d B)=\quad-10-(-69) \quad=59$ $d B m=29 d B$
Where Ptx is the transmitted optical power from the laser diode.Pmin is the minimum detectable power at the receiver unit. From equation 5 the optical power budget equal $29 \mathrm{~dB}$ and increases as the transmitted optical power increases.

\section{Conclusion:}

The encoded data stream shows successful demonstration of FSC generation techniques with high quality system of different fiber length(161.2) $\mathrm{km}$., so FCC code technique is better suited for optical communication because of the large output signal to noise ratio $\mathrm{S} / \mathrm{N}$ and low bit error rate $\mathrm{BER}$ of the received signal

\section{References:}

1.Wayne.Tomasi,1994."Electronic

Communication Systems,

Fundamentals Through Advanced" $2^{\text {nd }}$ edition ,Prentic Hall ,Newjersy, pp. 880

2.Matyas R.,1978. "Effect of Noisy Phase References on Coherent Detection of FFSK Signals", IEEE Tran.on Communication,Com-26.

3.Salehi,J.A.,1989"Code Division Multi-Access Technique in Optical Fiber Network - Part 1: Fundamental Principles ", IEEE Trans. Commun., 37:824-633

4.Meagher B.,Chang G.K.,Lin Y.M Robet and Way W.I.,2000 "Design and implemementation of Ultra-Low Latency Optical Label Switching for Packet - Switched WDM Network", J. of Light wave Technology,18: 1978-1987.

5.Leaird D.E JiangZ. And Weiner A. M,2005"Expermental Investigation of Security Issues in OCDMA:A Code -Switching Scheme",Electrons Lett.,41:89-90.

6.Jiang.Z, Seo D.S., Yang S.D., leaird D.E., Roussey R.V., Langrock.C. and WeinerA.M., 2005 "Four-User ,2.5-Gb/s Spectrally Coded OCDMA 
Four-User,2.5-Gb/s Spectrally Coded OCDMA System Demonstration Using Low Power Nonlinear Processing",J. of Light wave Technology, 23:143-156.

7.Mian,D. and chun Z., 2006 "A Wideband Frequency Shift Keying Demodulator for Wireless Neural Stimulation Microsystems" J. Zhejiang University,7(6 ):1056-1060
8.Attyah N.A. "Data Acquisition in Optical Communication Systems" M.Sc. Thesis University of Baghdad 2001.

9. Yassen I.A."Direct Analog Modulation of Radio Signal Via Optical Fiber " Thesis University of Baghdad 2004

\section{تصميم ويناء منظومة ترميز في انظمة اتصالات الالياف البصرية باستخدام تقتية

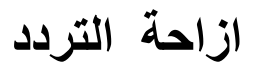

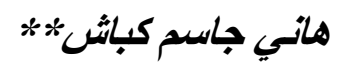

\author{
سمر بيونس الدباغ* \\ * * جامعة بغداد كلية العلوم للبنات/قسم الفيزياء. \\ ** * *امعة بغداد/ كلية العلوم /قسم الفيزياء.
}

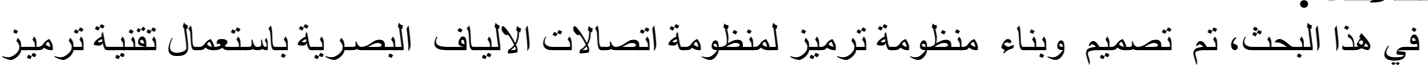

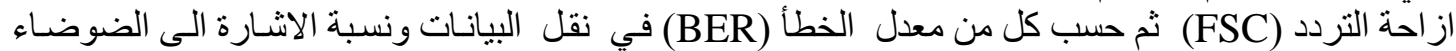
(S/N)

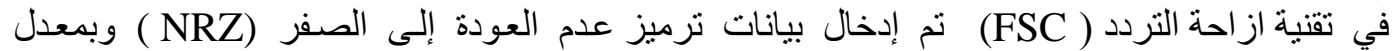

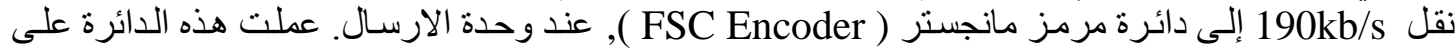

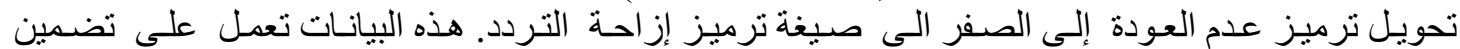

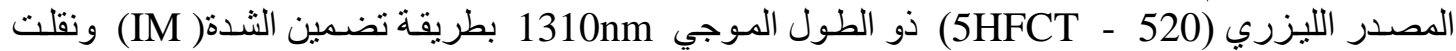

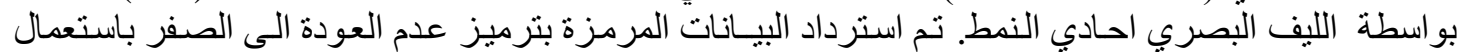

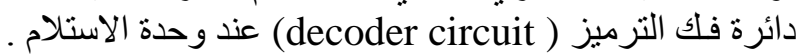

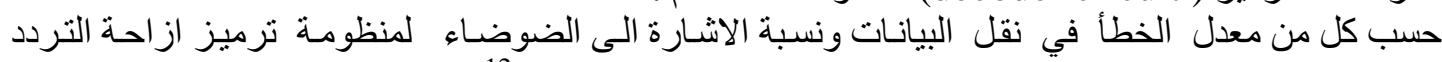

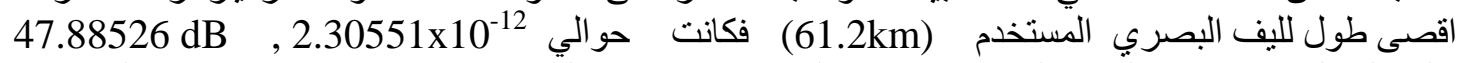

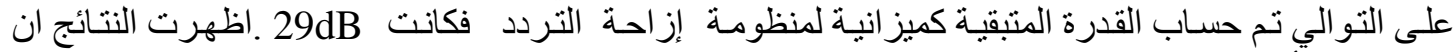

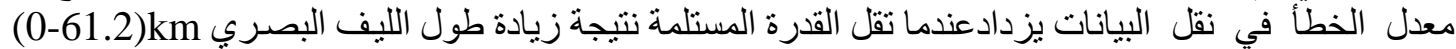

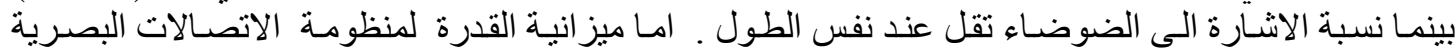

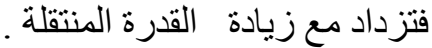

